\title{
Bibliometric Analysis of Highly Cited Papers on Resources and the Environment in China
}

\author{
Guosheng Han ${ }^{1,+}+\mathbb{D}$, Rundong Luo ${ }^{1,+}$, Kaiyue Sa ${ }^{2, *}$, Min Zhuang ${ }^{3}$ and Hui Li ${ }^{4}$ \\ 1 School of Business, Shandong University, Weihai 264209, China; hanguosheng@sdu.edu.cn (G.H.); \\ luorundong@sdu.edu.cn (R.L.) \\ 2 School of Finance, Shandong Technology and Business University, Yantai 264005, China \\ 3 School of Geographic and Oceanographic Sciences, Nanjing University, Nanjing 210023, China; \\ Minzhuang521@163.com \\ 4 School of Economics and Management, Harbin Institute of Technology, Weihai 264209, China; \\ lihui0528@hit.edu.cn \\ * Correspondence: 201913702@sdtbu.edu.cn \\ + These authors contributed equally to this work.
}

Citation: Han, G.; Luo, R.; Sa, K.; Zhuang, M.; Li, H. Bibliometric Analysis of Highly Cited Papers on Resources and the Environment in China. Sustainability 2022, 14, 604. https://doi.org/10.3390/su14020604

Academic Editors: Baojie He, Ayyoob Sharifi, Chi Feng and Jun Yang

Received: 28 October 2021 Accepted: 31 December 2021

Published: 6 January 2022

Publisher's Note: MDPI stays neutral with regard to jurisdictional claims in published maps and institutional affiliations.

Copyright: (c) 2022 by the authors Licensee MDPI, Basel, Switzerland. This article is an open access article distributed under the terms and conditions of the Creative Commons Attribution (CC BY) license (https:// creativecommons.org/licenses/by/ $4.0 /)$.

\begin{abstract}
To review the current state of resources and environmental sciences in China, this study assessed highly cited papers of five leading CSSCI journals sourced from the Chinese National Knowledge Infrastructure database. The fields of resources and environmental sciences were the research focus, and the bibliometric analysis software CiteSpace was used to perform co-occurrence analysis on keywords, authors, and research institutions based on bibliometrics and social network analysis. Furthermore, the research hotspots, scientist groups, and main cooperation models in the field of resources and environmental sciences in China were also explored. The results show that: (1) For 30 years, the interdisciplinarity of resources and environmental sciences has become more and more intense, and research themes have become increasingly extensive. The research hotspots of highly cited papers focused on energy, ecology, land, water resources, and sustainable development. In recent years, problems associated with energy and carbon emissions have aroused great interest. The ecological and sustainable development of resources and environmental elements has emerged as a future research trend. (2) An analysis of scientist-oriented networks shows that highly cited papers are mostly published by group authors. Scientists work closely within their respective academic groups, while intergroup academic cooperation is rare. Furthermore, connectedness between cooperation networks is poor, and scientists are largely connected through their research institutions. Cooperation among scientists is greatly affected by their geographical locations. Research institutions in the same region are more likely to cooperate. Beijing and Nanjing are high-producing areas of highly cited papers. The Institute of Geographic Sciences and Resources, CAS, is the most influential research institution. This paper introduces the state-of-the-art research hotspots of Chinese resources and environmental sciences to international academic circles and provides a basis for the research practice of resources and environmental sciences worldwide.
\end{abstract}

Keywords: resources and environment; highly cited paper; CiteSpace; research hotspot; scientist group; cooperation model

\section{Introduction}

While the core keywords for resources and environmental sciences are "resources" and "environment", these fields involve a wide range of research contents. The scope of research on "resources" and "environment" covers resources science, environmental science, geography, ecology, atmospheric science, geology, and many other disciplines [1]; therefore, academic research in this field is characterized by strong comprehensiveness and interdisciplinarity. Since entering the "14th Five-year Plan" period, China employs a particular emphasis on high-quality socioeconomic development, and topics on resources 
and the environment have received increasingly close attention. In particular, with the aggravation of resources utilization and environmental protection problems as a result of rapid economic development, how to reasonably utilize limited resources and effectively protect the environmental habitat have posed a hotspot research problem to Chinese society. In this context, it is quite meaningful and valuable to gain a systematic understanding of both the hot topics related to the development of resources and the environment and the academic research strategies employed by Chinese scientists in this field. In general, highly cited papers reflect the attention scientist groups divert to hotspots and urgent academic topics. For this reason, this study performed bibliometric analysis on highly cited papers in the field of environmental science in China using CiteSpace based on bibliometrics and social network analysis. The aim is to identify research hotspots of resources and environmental sciences, clarify their academic developments and future trends, provide research directions and a decision-making basis for both governance and academic research of resources and the environment, and promote the improvement of the academic system of resources and environmental sciences. The major research problems examined in this study are summarized as the following:

- The Research Progress of Resources Science in China Was Reviewed to Provide a Literature Basis for Discussing and Comparing the Results of This Study.

- The Research Institutions and Academic Groups of Highly Cited Papers in the Field of Resources and the Environment in China Were Assessed Based on Author Cooperation Networks.

- The Staged Development Characteristics of Resources and Environmental Research in China Were Explored.

- The Main Hot Topics in the Field of Resources and the Environment in China Were Discussed Based on the Statistics of Top Keywords through a Cluster Analysis of Co-Occurring Keywords.

On this basis, the remaining sections of this study are organized as follows: Section 1 introduces specific research problems. Section 2 reviews the existing literature on resources and the environment in China. Section 3 describes the methods for data collection and analysis. Section 4 presents empirical results. Section 5 draws research conclusions and points out directions for future research.

\section{Literature Review}

\subsection{International Bibliometric Studies in the Field of Resources and the Environment}

Many bibliometric studies in international academic circles have followed the latest research progress of resources and the environment. Several of these studies dive into a specific theory, such as the theory of planned behavior [2] or biofuel energy [3]. Others are dedicated to comprehensive research on a specific problem associated with resources and the environment, such as Global Sustainable Livelihood Research [4]. There are also bibliometric studies that focus on a certain discipline in the field of resources and environmental research, such as resources and environmental sociology [5]. Regarding highly cited papers, bibliometric studies have been conducted on urban public safety [6] and resource conservation and recycling [7], but the overall status of resources and environmental research in China has rarely been investigated with a holistic approach. As China has made extensive achievements in the utilization and conservation of resources and the environment, international academic circles are eager to better understand China's latest academic topics, research institutions, academic groups, and academic development processes in this field. Against this background, this paper attempts to fill this research gap in international academic circles.

\subsection{Chinese Bibliometric Studies on Resources and the Environment}

Resources and environmental sciences are consistent with "resources science" and "environmental science" in research contents and research objectives, respectively, but they have different names in different research institutions. There is a lack of retrospective 
studies on the disciplinary development of resources and development internationally, especially those based on bibliometrics. As a research method, bibliometrics is often adopted by Asian scholars. Xu et al. identified four academic fields in international environmental science through a co-occurrence analysis of keywords, namely disposal and comprehensive utilization of industrial wastes, environmental dynamics and catalyst chemistry, environmental ecology and water-land resource conservation, and urban environmental management [8]. Existing studies on the hotspots and trends of resources and environmental science research in China tend to start from a single perspective. Only a few researchers have probed into the development of "environmental science" and "resources science".

Depending on the research methods adopted, existing studies can be roughly classified into two categories, i.e., qualitative and quantitative studies. Qualitative studies summarize disciplinary research results based on an existing knowledge base and literature, while quantitative studies perform quantitative analysis on existing studies by technical means based on bibliometrics.

\subsubsection{Qualitative Studies on Resources and the Environment in China}

Gao reviewed the disciplinary connotations, research tasks, and development trends of resources and environmental sciences based on studies on "resources science" and "environmental science" [9]. Du elaborated on the research progress of environmental science from the perspective of changes in the disciplinary origin, disciplinary settings, and research problems of environmental science [10]. Tong et al. analyzed the development of the theoretical connotations and denotations of environmental science [11]. Based on reviewing existing literature, $\mathrm{Li}$ and Leng introduced several basic concepts of environmental science and compared the basic situations of China and the US in this field in terms of specialized education, disciplinary research, and financial support [12]. In summary, these studies have elaborated on the basic theories and research progress of environmental science from a macroscopic perspective. With the rapid development of environmental science towards interdisciplinary fusion and large-scale in-depth development and the constant appearance of emerging research fields and subjects, studies in this field are shifting from subjective judgment to scientific measurement. In addition, studies that employ qualitative methods and tools to explore the laws and trends of disciplinary development are also increasing.

\subsubsection{Bibliometric Studies on Resources and the Environment in China}

In 2006, Xu and Liu conducted a survey on international environmental science journals using Bibexcel and SPSS and identified the mainstream research fields of international environmental science. This was the first time the academic fields of environmental science were analyzed by Chinese researchers using scientific measurement software [8]. In 2016, Lin and Yang investigated the hotspots and development of environmental science based on bibliometrics. Taking the category of "environmental science and resources utilization" from CNKI as the data source, they selected four journals with high comprehensive standards (i.e., Environmental Science, Acta Scientiae Circumstantiae, China Environmental Science, and Research of Environmental Sciences) and performed co-occurrence analysis on the keywords of all papers published over 20 years using SATI software [13]. However, they did not address the research hotspots or development trends of environmental science. Huo analyzed the changing trends of the research hotspots of resources and environmental sciences based on the distribution statistics of projects supported by the National Natural Science Foundation of China (NSFC), showing that currently, energy consumption and economic development are the main research hotspots in this field [14].

In terms of author cooperation models, Dang assessed the relationships between institutions through social network analysis by focusing on the cooperation between institutions of higher learning but failed to conduct an in-depth analysis of the underlying substantial relationships [15]. In certain special cases, scholars reviewed the development of resources and environmental sciences by the Chinese Academy of Sciences (CAS). Sun introduced the development of resources and environmental research by CAS in 
1989 [16]. In 2009, Ding et al. outlined the 60-year development history of resources and environmental sciences at CAS [1]. In 2015, Wang et al. conducted a statistic analysis of the paper output by CAS in the fields of resources, environment, and earth science in 2009-2014. They identified the research output and development status of CAS in the field of resources and the environment [17]. These studies have analyzed the development of research institutions of resources and environmental sciences and improved researchers' understanding of the output and development of such institutions.

Overall, Chinese studies on the disciplinary development of resources and environmental sciences mostly focus on theories, concepts, disciplinary settings, and specialized education. Even studies dedicated to analyzing research hotspots and trends merely concentrate on environmental science or resources science, without diving into the field of resources and environmental sciences in a holistic, comprehensive, and systematic manner. Moreover, there is also a lack of objective, quantitative scientific studies in this field. In this context, this study aimed to distinguish the disciplinary knowledge structure of resources and environmental sciences using CiteSpace (scientific knowledge map) and identify relevant research hotspots. CiteSpace is a visualization tool reflecting the evolution of knowledge domains. It is often used to analyze the development trends and models of the scientific literature [18]. CiteSpace is more advanced than other existing quantitative software in two aspects: First, it adopts citation network analysis that has integrated the idea of social network analysis. Second, it introduces a visualization map into network analysis. Relying on its strengths in the above two aspects, CiteSpace can more visually and clearly mirror the research hotspots, cooperation relationships, and research trends in the field of environmental science and more effectively help to grasp disciplinary development both at the detailed level and overall. The citation frequency of a paper reflects the importance attached to the paper and the quality of the corresponding research and facilitates understanding of the subsequent development of the research. Investigating highly cited papers helps to the assess academic level and journal quality and understand disciplinary research directions [19]. However, so far, there is still a lack of studies on highly cited papers in the field of resources and environmental sciences.

Considering this, this study first selected the resources and environmental journals included by CSSCI using the scientific knowledge map software CiteSpace based on bibliometrics and social network analysis. Next, academic papers published by five CSSCI journals (i.e., China Population, Resources and Environment; Resources Science; Journal of Natural Resources; Resources and Environment in The Yangtze Basin; and Arid Land Resources and Environment) since the initial issue were retrieved. Finally, taking the highly cited papers of the five CSSCI journals sourced from CNKI as the research object, CiteSpace was used to perform co-occurrence analysis on keywords, authors, and research institutions. The aim was to identify the development status of resources and environmental sciences, understand their research hotspots and author cooperation models, and provide a decision-making basis for the research and practice of resources and environmental sciences in the future.

\section{Research Methods}

\subsection{Methodology}

Bibliometrics and social network analysis constitute both the methodological foundation of this study and the methodological mechanism utilized by CiteSpace. Bibliometrics employs quantitative statistical methods to analyze the statistical characteristics (e.g., scientific terms, citations, authors, and publication time) of existing literature, thus clarifying the development laws of specific disciplines [19]. Social network analysis, which originated from sociometrics, is a set of normative methods developed to analyze social relationships and structures. It uses the network structures composed of the inner connections between different social actors as the research object and focuses on the connections between individuals instead of the characteristics of individuals [20]. 


\subsection{Data Collection}

While there are numerous resources and environmental science journals, this study selected five specific journals (i.e., China Population, Resources and Environment; Resources Science; Journal of Natural Resources; Resources and Environment in The Yangtze Basin; and Arid Land Resources and Environment) from the journals included by CSSCI and retrieved the academic papers from CNKI (1), without any time limitation. Eventually, a total of 19,523 entries of retrieved results were obtained and ranked by total citation frequency.

Highly cited papers are generally determined according to three methods: (1) the fixed citation frequency method, which is simple but highly subjective and lacks a scientific basis; (2) the Price Index method, which has a solid academic foundation but requires a large sample size and clear citation distribution laws; and (3) the percentage method, which is based on bibliometrics and characterized by strong scientificity and wide application [21] This study adopted the percentage method to determine highly cited papers by selecting the top $1 \%$ of papers in terms of their total citation frequency. The methods commonly used for data retrieval and screening are the synchronic method and the diachronous method. The synchronic method directly performs data screening according to established criteria, without considering the time factor. The diachronous method requires the statistics of the annual citation frequency of papers as input, establishes the annual high citation criteria, and screens highly cited papers of each year. This method poses great difficulties in preparing the statistics of the annual citation frequency and screening of papers [21]. Therefore, to balance accuracy and costs, the synchronic percentage method was adopted, and the top $1 \%$ of papers in terms of total citation frequency were identified as highly cited papers. Eventually, a total of 195 highly cited papers were obtained. To remedy the limitation of the synchronic method, due consideration was given to the time factor, and two, two, and one papers were selected with the highest total citation frequency for the years of 2018, 2019, and 2020, respectively. In this way, 200 papers were obtained. A subsequent check showed that there were no informative papers (such as instructions for authors, conference notices, or reviews); therefore, all 200 papers were used. Table 1 provides the descriptive information on 200 selected highly cited papers. Table 2 illustrates the distribution of these papers across different journals.

Table 1. Descriptive information on 200 selected highly cited papers.

\begin{tabular}{|c|c|c|c|c|c|c|}
\hline $\begin{array}{l}\text { Number of } \\
\text { Papers }\end{array}$ & Total Citations & $\begin{array}{l}\text { Maximum } \\
\text { Citations per } \\
\text { Paper }\end{array}$ & $\begin{array}{l}\text { Minimum } \\
\text { Citations per } \\
\text { Paper }\end{array}$ & $\begin{array}{c}\text { Average Citations } \\
\text { per Paper } \\
\text { (Endpoint Values } \\
\text { Removed) }\end{array}$ & $\begin{array}{c}\text { Earliest } \\
\text { Publication } \\
\text { Year }\end{array}$ & $\begin{array}{c}\text { Latest } \\
\text { Publication } \\
\text { Year }\end{array}$ \\
\hline 200 & 59,966 & 2353 & 7 & 288.03 & 1987 & 2021 \\
\hline
\end{tabular}

Table 2. Distribution of sample journals.

\begin{tabular}{|c|c|c|c|c|c|}
\hline Journal Name & $\begin{array}{l}\text { China Population, } \\
\text { Resources and } \\
\text { Environment }\end{array}$ & Resources Science & $\begin{array}{c}\text { Journal of Natural } \\
\text { Resources }\end{array}$ & $\begin{array}{l}\text { Resources and } \\
\text { Environment in } \\
\text { The Yangtze Basin }\end{array}$ & $\begin{array}{c}\text { Arid Land } \\
\text { Resources and } \\
\text { Environment }\end{array}$ \\
\hline Year of initial issue & 1991 & 1998 & 1986 & 1992 & 1987 \\
\hline $\begin{array}{l}\text { Total number of } \\
\text { papers }\end{array}$ & 1536 & 4102 & 3440 & 3964 & 6481 \\
\hline $\begin{array}{l}\text { Number of highly } \\
\text { cited papers included }\end{array}$ & 4 & 59 & 113 & 18 & 6 \\
\hline
\end{tabular}




\subsection{Data Analysis}

The 200 papers were converted using CiteSpace V. Time slicing and threshold were set, while other options used default settings. Analysis was performed on the co-occurrence of keywords and subjects and the cooperation models between authors as well as research institutions.

Notes

1. Professional retrieval: JN = 'China Population · Resources and Environment' + 'Arid Land Resources and Environment' + 'Resources Science' + 'Journal of Natural Resources' + 'Resources and Environment in The Yangtze Basin'.

2. Top N\% per slice refers to the data of the top N\% (less than $\mathrm{M}$ ) highly cited papers or high-frequency nodes for each period.

3. Module values ( $Q$ values) generally fall within the interval of $(0,1)$. " $Q>3$ " means that the partitioned community structure is significant. If average silhouette coefficient values ( $\mathrm{S}$ values) exceed 0.5 , the clusters are generally held to be reasonable. When they exceed 0.7 , the clusters are deemed efficient. When they are infinite, the cluster number is 1 , in which case the network selected would be too small to represent more than one research subject.

\section{Research Results}

\subsection{Resources and Environmental Research Institutions in China}

In this study, a statistical analysis was performed on 10 research institutions which had each published more than five highly cited papers, as they constituted the backbone force of scientific research in the field of resources and the environment (Table 3). According to the results of the analysis, the Institute of Geographic Sciences and Natural Resources Research, CAS, is the most influential research institution in the field of resources and environmental sciences in China. It has published 97 highly cited papers, accounting for $32.23 \%$ of the total number of highly cited papers. Ranked in the second echelon were institutions of higher education such as Nanjing University and Peking University. Judging from the distribution of research institutions in different research areas, Beijing and Nanjing are high-producing areas of highly cited papers in the field of resources and environmental science research in China. In particular, Beijing is at the top in this regard. Judging from the nature of research institutions, high-quality papers are still predominantly published by scientific research institutions and institutions of higher education, while extraordinary high-level corporate research institutions are rarely involved.

Table 3. Main resources and environmental research institutions in China.

\begin{tabular}{ccc}
\hline Institutions & Frequency & Percentage \\
\hline Institute of Geographic Sciences and Natural Resources Research, CAS & 84 & 28 \\
Nanjing University & 26 & 9 \\
Peking University & 24 & 8 \\
Beijing Normal University & 24 & 8 \\
Research Center for Eco-Environment Sciences, CAS & 18 & 6 \\
China Agricultural University & 18 & 6 \\
Nanjing Agricultural University & 13 & 4 \\
Eommission for the Integrated Survey of Natural Resources, CAS & 13 & 4 \\
East China Normal University & 10 & 3 \\
Institute of Remote Sensing and Digital Earth, CAS & 6 & 2 \\
\hline
\end{tabular}

Cluster analysis was performed on the cooperation between research institutions to identify the cooperation status between resources and environmental research institutions in China. According to analysis results, $Q=0.5204$, and $S=0.1647$, as shown in Figure 1 The clustering results were not apparent, suggesting that the efficiency of cooperation between research institutions is low. Currently, author cooperation models for the output of high-quality papers are specific, and research institutions are relatively isolated from 
each other, without frequent exchanges or cooperation. Their academic connections are largely concentrated in one region. Taking Nanjing as an example, a research group has taken shape based on the city, including the Institute of Soil Science, CAS; the Department of Urban and Resources Sciences, Nanjing University; the Nanjing Institute of Geography and Limnology, CAS; and the Land Research Center, Nanjing Agricultural University.

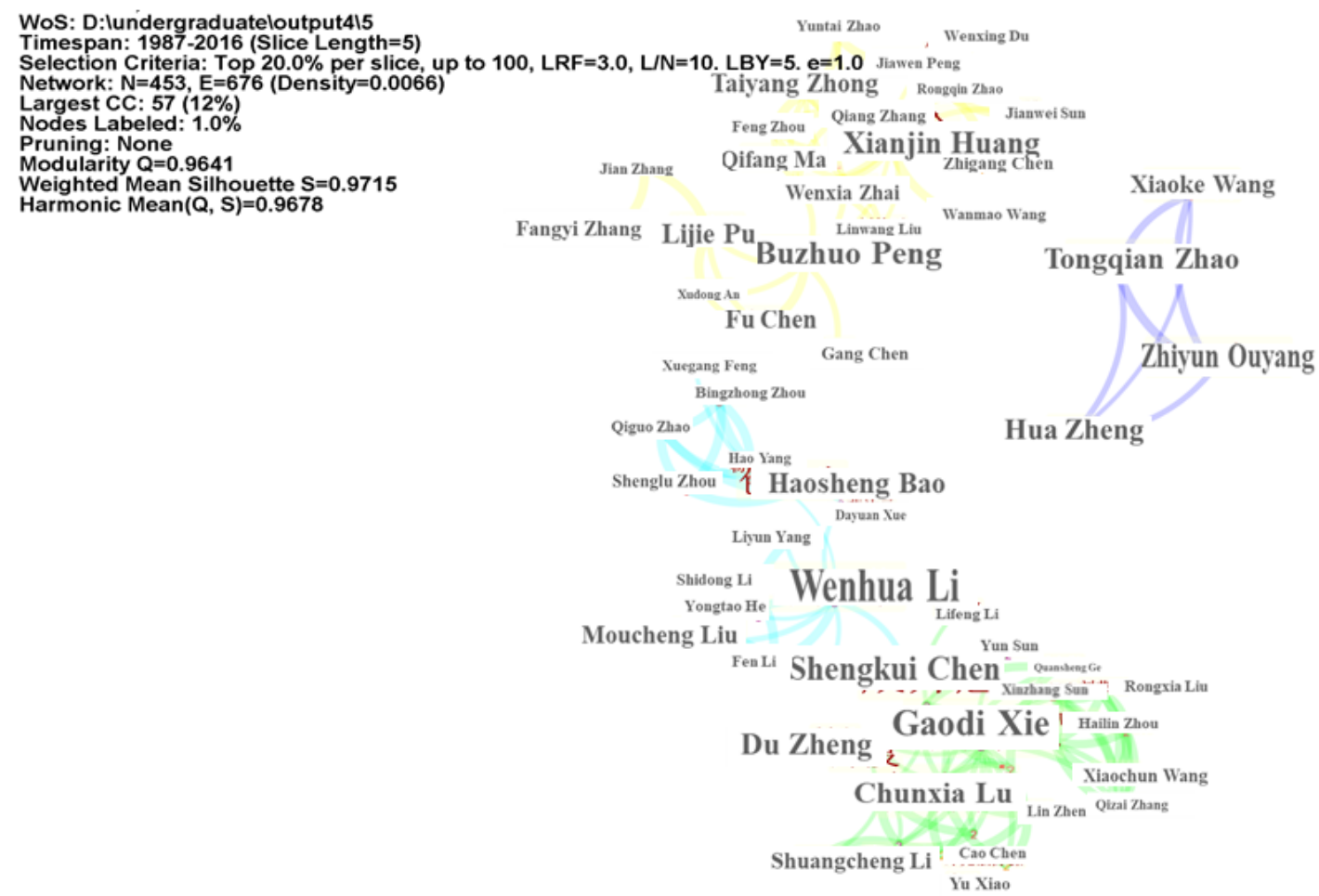

Figure 1. Co-authors network.

\subsection{Core Research Groups of Resources and the Environment in China}

Qiu classified author cooperation networks into four types: (1) single-point type-an author point where the author publishes papers independently; (2) binuclear type-a network in which two authors cooperate in publishing papers; (3) core type-a network in which the core point author is connected with other authors, presenting a pattern of outward radiation from the center; (4) bridge type-a network in which one or two authors play the role of bridges between two cooperative subgroups [22]. In this study, co-occurrence analysis was performed on authors using CiteSpace to reflect the cooperation between authors more visually (time slicing $=5$, threshold $=$ TOP20\%). Cluster analysis was also conducted to map the author cooperation networks of highly cited papers (Figure 1). According to clustering results, $Q=0.809$, and $S=0.589$, so the cluster structure can be regarded as significant with reasonable efficiency. As illustrated in Figure 1, highly cited papers are completed in most cases through cooperation between authors, and in a few cases independently by individual authors. In the earlier stage before the 1990s, most papers were published by independent authors, because most university faculties were teaching focused and most academic studies were confined to the scientific institutions and such very few comprehensive universities as Beijing University, Tsinghua University, Nanjing University, and so on. Since the 1990s, universities have been classified into teaching and research focused. The Chinese government sponsored huge research projects aimed to respond to national sustainable development strategy. More and more universities and research institutions cooperated, setting up huge research groups to cope with national synthetical projects in the resources and environment field. Thus, more papers were coauthored in a group authorship form mainly from a research group and some from across-group cooperation. 
In the major author cooperation networks of China in the field of resources and environmental sciences (Figure 1), there are apparently five single-point-type sub-networks, four binuclear-type sub-networks, and five core-type sub-networks. Scholars in single-point type sub-networks are often capable of completing scientific research tasks independently, but, in general, high-quality papers are completed through teamwork. In particular, after entering the stage of complex multidisciplinary systems, scholars in the field of resources and environmental sciences need to possess interdisciplinary scientific research knowledge and related abilities. Cooperation of the binuclear type generally consists of cooperation between colleagues from the same institution and cooperation between tutors and students; therefore, cooperation relationships are relatively stable. A core-type sub-network may also include multiple bridge-type sub-networks. One core-type sub-network often represents one co-author group. Analysis of the five core-type sub-networks showed that cooperation within groups is frequent, but intergroup connectivity and cooperation are rare (Figure 1).

Group 1: This group is affiliated with the Research Center for Eco-Environmental Sciences, CAS, and mainly focuses on ecosystem service functions. Scholars such as Tongqian Zhao and Zhiyun Ouyang formed the first group of scholars to engage in ecosystem services research in China.

Group 2: The authors of this group constitute the core publishing group in the field of resources and environmental sciences and are all members of the Institute of Geographic Sciences and Natural Resources Research, CAS. Gaodi Xie, Shengkui Cheng, Chunxia $\mathrm{Lu}$, and $\mathrm{Du}$ Zheng formed the core subgroup and published several highly cited papers from 2001 to 2006. In this period, Gaodi Xie served as the principal (first) author. The main cooperation direction was the value assessment of ecosystem services. For instance, the value assessment of the ecological assets of the Qinghai-Tibet Plateau and natural meadows posed an important research task to resources and environmental sciences in China. With the increasing recognition of scholars and their increasing influence, they began to strengthen their external cooperation, thus forming new cooperation groups. Around 2009-2010, Gaodi Xie and Wenhua Li (Group 6) co-authored a highly cited paper on the ecosystem service functions of forests. Later, the group constantly absorbed new scholars, which testified to the dynamic development of author cooperation networks. The joining of new scholars also pointed to new research directions for and injected new vitality into this group, leading to the continuous output of high-quality papers.

Group 3: This group has published less highly cited papers than other groups in the field of resources and environmental sciences. Haosheng Bao is the core author of this group, the research directions of which covered land-use change, tourism systems, and resources and the environment. In the field of resources and environmental sciences, Haosheng Bao, Shenglu Zhou, and Hao Yang are all members of Nanjing University, and their cooperation direction concentrates on land-use change.

Group 4: Xianjin Huang, Qifang Ma, Wenxia Zhai, and Taiyang Zhong take intensive land use as their primary research direction. Since 2008, Xianjin Huang has published several highly cited papers in the fields of resources economy, energy utilization, and carbon emissions.

Group 5: Buzhuo Peng, Lijie Pu, Fu Chen, and Gang Chen are all members of Nanjing University. They engaged in cooperative publishing on land resource management, land use, and cultivated land quality in 2006-2009.

Group 6: Some scholars (e.g., Wenhua Li, Moucheng, Liu, and Liwen Yang) from the Institute of Geographic Sciences and Natural Resources Research, CAS, focused on issues concerning the forest and ecology.

In summary, teamwork is established via scientific research institutions, and different groups have different research directions (Table 4). Betweenness centrality measures the ability of the center points in the network to function as mediators in social networks, thus controlling communication between other members. In the five cooperative groups, authors with a strong control ability in Groups 2 and 3 are Gaodi Xie and Haosheng Bao, respectively. This suggests that these scholars, as bridges between sub-networks, play leading roles 
in the information exchange, opinion communication, and action coordination links of academic cooperation. Wenhua Li, as the mediating scholar between Groups 2 and 3 with a betweenness centrality value of 0.03 , also serves as a bridge between major sub-networks. In contrast, the authors of other groups are relatively independent of each other.

Table 4. Author cooperation subgroups.

\begin{tabular}{cccc}
\hline No. & Group Member & Research Direction & Employer Institution \\
\hline 1 & $\begin{array}{c}\text { Tongqian Zhao Zhiyun, Ouyang, Xiaoke } \\
\text { Wang, Hua Zheng }\end{array}$ & Ecosystem services & $\begin{array}{c}\text { Research Center for Eco-Environmental } \\
\text { Sciences, CAS }\end{array}$ \\
2 & $\begin{array}{c}\text { Chunxia Lu, Gaodi Xie, Shengkui Cheng, } \\
\text { Du Zheng }\end{array}$ & $\begin{array}{c}\text { Ecology, soil science } \\
\text { Institute of Geographic Sciences and } \\
\text { Natural Resources Research, CAS } \\
\text { Nanjing University }\end{array}$ \\
4 & $\begin{array}{c}\text { Haosheng Bao, Shenglu Zhou, Hao Yang } \\
\text { Xianjin Huang, Qifang Ma, Wenxia Zhai, } \\
\text { Taiyang Zhong }\end{array}$ & $\begin{array}{c}\text { Physical nature } \\
\text { Lesources and environment, }\end{array}$ & Nanjing University \\
5 & Buzhuo Peng, Lijie Pu, Fu Chen, & Land resource management & Nanjing University \\
6 & Wenhua Li, Moucheng Liu, Liwen Yang & Forest and ecology & $\begin{array}{c}\text { Institute of Geographic Sciences and } \\
\text { Natural Resources Research, CAS }\end{array}$ \\
\hline
\end{tabular}

\subsection{Evolution of the Research Hotspots of Resources and Environment Sciences in China \\ 4.3.1. Distribution and Frequency of Keywords}

Keywords represent the research subjects, contents, theories, methods, perspectives, and other characteristics of papers. The frequency of keywords in highly cited papers reflects the situation of hotspot problems. In this study, statistics were gathered of the top keywords of 200 highly cited papers from CNKI, and keywords with consistent semantics were merged, as detailed in Table 5. The major research areas in the field of resources and environmental sciences in China mainly include Jiangsu Province, Beijing, Zhejiang Province, the Yangtze River Delta and its adjacent agglomerations, the Qinghai-Tibet Plateau, the Loess Plateau, and the arid and semi-arid areas in northwestern China. These areas are highlighted for four reasons: (1) concentration of scientific research strength-for instance, there are many productive resources and environmentally oriented scientific research institutions and institutions of higher education in Beijing and Jiangsu; (2) economic strength-for instance, Beijing, Shanghai, and Zhejiang are all economically developed areas in eastern China; (3) focus of journals-for instance, Resources and Environment in The Yangtze Basin mainly focuses on the Yangtze Basin; (4) particularity of resources and environmental problems-for instance, the ecosystems of the Qinghai-Tibet Plateau and the arid and semi-arid areas of northwest China are very vulnerable and special. In terms of research contents, the keywords of the 200 highly cited papers are concentrated on land resources, water resources, population, food, policies, environment, ecology, sustainable development, and the evaluation index system and basically cover all research hotspots in this field. To be noted, the great differences in the word frequency of each research field as shown in Table 5 may indicate that the word frequency in some traditional and mature themes is comparatively larger while lower in some new and emerging themes to some extent. The difference in the word frequency may be explained by the evolutions of the themes in the field, and we would suggest that international colleagues pay more attention to these themes with lower word frequencies in the analysis. 
Table 5. Analysis of top keywords in the field of resources and environmental sciences in China.

\begin{tabular}{|c|c|c|c|}
\hline Keywords & Frequency & Keywords & Frequency \\
\hline Land use & 49 & Prediction & 4 \\
\hline China & 38 & Influencing factors & 4 \\
\hline Water resources & 31 & Bearing capacity & 3 \\
\hline Land-use type & 29 & Environmental resources & 3 \\
\hline Index system & 21 & Technological progress & 3 \\
\hline Evaluation & 19 & Natural reserve & 3 \\
\hline Economic development & 18 & Runoff & 3 \\
\hline Sustainable development & 18 & Net primary productivity & 3 \\
\hline Ecosystem service functions & 14 & Residential land & 3 \\
\hline Urbanization & 14 & Energy value analysis & 3 \\
\hline Eco-environment & 13 & Population growth & 3 \\
\hline Land cover change & 13 & Entropy & 3 \\
\hline Food production & 12 & Ecological security & 3 \\
\hline Biological production & 10 & Ecological planning & 3 \\
\hline Land resources & 9 & $\begin{array}{l}\text { Ecological resources } \\
\text { management }\end{array}$ & 3 \\
\hline Spatial analysis & 8 & Biodiversity & 3 \\
\hline Agriculture & 8 & Land evaluation & 3 \\
\hline Cultivated land & 7 & Soil conservation & 3 \\
\hline Regional differences & 7 & Evapotranspiration & 3 \\
\hline Driving force analysis & 7 & Exponential sum & 3 \\
\hline Human activities & 7 & Policy suggestions & 2 \\
\hline Ecological bearing capacity & 7 & GI & 2 \\
\hline Climate change & 6 & NDVI & 2 \\
\hline Ecological footprint & 6 & Countermeasures & 2 \\
\hline Output factor & 5 & Wind effect index & 2 \\
\hline Ecotourism & 5 & Coupling & 2 \\
\hline $\begin{array}{l}\text { Geographical information } \\
\text { system (GIS) }\end{array}$ & 5 & Service functions & 2 \\
\hline Rural settlement & 5 & Lake & 2 \\
\hline Global change & 5 & Straws & 2 \\
\hline Forest cover & 5 & Landscape ecology & 2 \\
\hline Ecological protection & 5 & Connotations & 2 \\
\hline Ecological deficit & 5 & Energy consumption & 2 \\
\hline Carbon emissions & 5 & Potential & 2 \\
\hline Coordination degree & 5 & Ecological economics & 2 \\
\hline Willingness to pay & 5 & Model & 2 \\
\hline Environmental problems & 4 & Eco-civilization construction & 2 \\
\hline Forest ecosystem & 4 & $\begin{array}{c}\text { Eco-environmental water } \\
\text { demand }\end{array}$ & 2 \\
\hline Land degradation & 4 & Information entropy & 2 \\
\hline Land erosion & 4 & Research progress & 2 \\
\hline Temperature-humidity index & 4 & Remote sensing & 2 \\
\hline
\end{tabular}

\subsubsection{Identification and Analysis of Research Hotspots}

Different keywords co-occurring at a higher frequency in one paper implies that they have closer inner relationships and shorter distances between each other [23]. By performing cluster analysis on keywords, hotspot keywords in a discipline can be classified, and research hotspots, bases, and frontiers can be identified. In this study, a co-occurrence analysis of keywords was first conducted for the 200 highly cited papers (time slicing $=5$, threshold $=$ TOP20\% (2)). A knowledge map of keyword co-occurrence was obtained with 52 nodes and 50 links. Next, cluster analysis was performed which identified 17 keyword cluster networks, including five cluster networks with interconnections and 12 independent cluster networks. According to the results depicted in Figure $2, Q=0.7403$, and $S=0.5189$; therefore, the cluster can be regarded as reasonable. The colors of the knowledge map indicate that the field of resources and environmental science research in China entered 
its high-producing period in 1997, when it began to produce high-quality papers in large numbers. Finally, the 17 clusters were partitioned according to co-occurrence connections and knowledge bases.

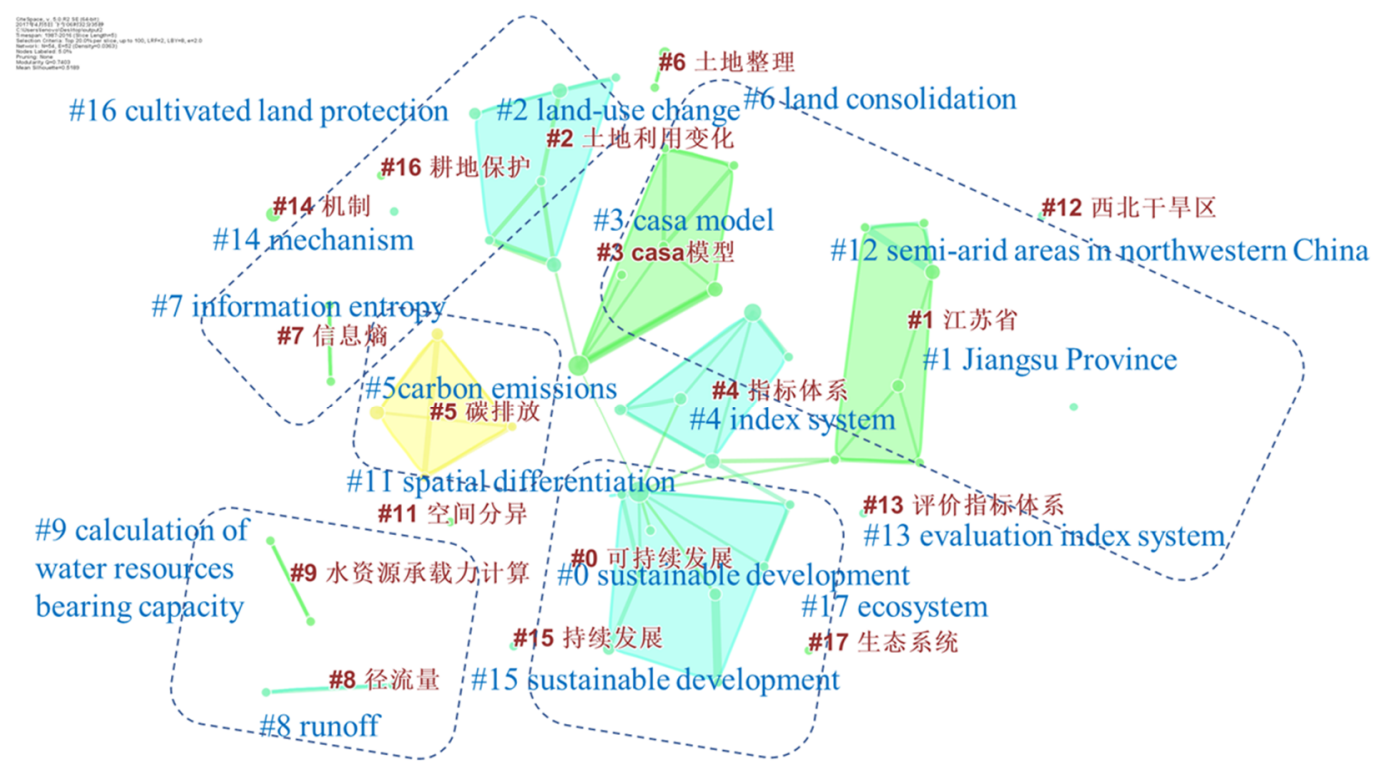

Figure 2. Keyword co-occurrence cluster.

Clearly, highly cited papers in the field of resources and environmental sciences in China can be clustered into five research categories, each based on a different research perspective (Table 6).

Table 6. Cluster partitioning of keyword co-occurrence.

\begin{tabular}{|c|c|c|}
\hline Research Category & Research Hotspots & Clustering Tag \\
\hline Energy & $\begin{array}{l}\text { Energy consumption-carbon } \\
\text { emissions-economic development }\end{array}$ & \#5 carbon emissions \\
\hline Ecology & $\begin{array}{c}\text { Ecosystem service functions-index system } \\
\text { Ecological security-ecological } \\
\text { Footprint-eco-compensation-ecological } \\
\text { planning } \\
\text { Eco-civilization construction-mechanism }\end{array}$ & $\begin{array}{c}\text { \#3 casa model \#4 index system \#17 ecosystem } \\
\text { \#1 Jiangsu Province } \\
\text { \#10 eco-civilization construction }\end{array}$ \\
\hline Land resources management & $\begin{array}{l}\text { Land use-land planning-land cover } \\
\text { Soil governance-cultivated land } \\
\text { protection-food security }\end{array}$ & $\begin{array}{l}\text { \#2 land-use change \#6 land consolidation \#7 } \\
\text { information entropy \#11 spatial differentiation } \\
\text { \#16 cultivated land protection \#14 mechanism }\end{array}$ \\
\hline Water resources management & $\begin{array}{l}\text { Water security-water bearing } \\
\text { capacity-pollution governance }\end{array}$ & $\begin{array}{c}\# 12 \text { semi-arid areas in northwestern China \#9 } \\
\text { calculation of water resources bearing capacity } \\
\text { \#8 runoff }\end{array}$ \\
\hline Sustainable development & Sustainable development of various elements & $\begin{array}{l}\# 0 \text { sustainable development \#13 evaluation } \\
\text { index system \#15 sustainable development }\end{array}$ \\
\hline
\end{tabular}

\section{- $\quad$ Energy}

The selected highly cited papers on carbon emissions mainly focus on the period of 2009-2014, suggesting that currently, carbon emissions constitute a research hotspot in the field of resources and environmental sciences. Correspondingly, low-carbon emission reduction and ecological protection have become important research frontiers. According to the keyword cluster "\#5 carbon emissions", domestic studies on carbon emissions mainly focus on the accounting and decomposition of carbon emissions, the influencing factors, and the relationship between carbon emissions and economic development. The increasing intensification of haze pollution in China has given rise to a series of policies on low-carbon 
emission reduction, and many studies addressed carbon emissions and haze governance. In 2015, Wei and Ma simulated the combination of policies on energy, technology, and haze using an econometric model [24]. Given China's heavy dependence on coal resources, carbon emissions will likely remain a major research problem in the field of resources and environment sciences over the course of energy restructuring. The distribution trend of scientific research funds also presents the priorities of research fields. Currently, more than $50 \%$ of the projects supported by the NSFC in the field of resources and environmental science focus on energy and carbon emissions [14], which corroborates the findings of the present study.

\section{- Ecology}

Ecology is the science of the interactions between organisms and the environment. The term "ecology" has appeared in the titles of 48 of the 200 highly cited papers and has occurred 81 times in total in the "Keywords" sections of the 200 highly cited papers. Because highly cited papers were published on ecology each year from 1987 to 2013, ecology constitutes an important knowledge base and a major research direction for resources and environmental sciences. Depending on specific ecology research perspectives, the research hotspots in this category can be divided into three classes:

(1) Assessment of ecosystem service functions and values: The concept of "ecosystem service functions" was introduced to China in the 1990s and experienced its high-producing period in 2002-2006. The papers published on this concept mainly focus on service functions, measurements, indices of different ecosystems, the value assessment of specific ecosystem service functions, and the effects of human activities. Typical cases include the ecosystems of the Qinghai-Tibet Plateau and the Loess Plateau, the forest ecosystem of the Changbai Mountains, and the desert ecosystem of semi-arid areas in northwestern China.

(2) Measurement and evaluation of the ecological footprint and research on ecological planning: The ecological footprint is an index for measuring sustainable development, and ecological planning is an approach for realizing sustainable development. The specific research contents include the measurement and evaluation of the ecological footprint of a specific space or activity, as well as the establishment of economic functions and ecocompensation mechanisms. Typical cases in this regard are the tourism ecological footprint measurements of Sichuan Province and Jiuzhaigou Valley.

(3) Eco-civilization construction and policy suggestions: Eco-civilization construction is a green, sustainable development pattern proposed by China. Research includes connotation theories, system construction, development paths, development effects, and development assessment. The keyword "eco-civilization construction" appeared frequently in 2012-2016, a period when the state made the strategic decision of "energetically promoting eco-civilization construction". The political, economic, and environmental significance of eco-civilization construction determines that it will remain an important research topic into the future.

\section{- $\quad$ Land resources management}

The interdisciplinarity between land resources management and resources and environmental sciences is becoming increasingly strong. Land is not only an essential natural resource, but also a spatial environment in the sense of physical existence. Land problems related to resources and the environment include land use problems and soil problems.

(1) Land use problems: The keyword cluster "\#2 land-use change" appeared in 1997-2001, and prominent keywords included "land cover", "GI", "land-use change", "driving factors", "ecological footprint", and "global change". The research problems included the type, change, investigation, and evaluation of land use. With the emergence of the concepts of global change and sustainable development, intensive land use became a hotspot research direction. In 2002-2006, the research contents of land use became more extensive. Prominent keywords in the cluster of "\#6 land consolidation" included "residential land" and "land consolidation". Prominent keywords in the cluster of "\#7 information entropy" included "land use structure" and "information entropy". Cluster "\#11 spatial 
differentiation" refers to the spatial differentiation of various areas after land use planning. In this period, the problems concentrated on the structure, planning, and change of land use; the driving forces of land-use change; and the measurement model and its effects. In the past five years, no outstanding highly cited paper has been published on land use, suggesting that studies in this field are still focusing on issues such as intensive land use and ecological protection and land-use change and global change. The hotspot research trend is to reasonably use and effectively protect land from an ecological point of view for meeting the growing demands of humans for land.

(2) Soil problems: Clusters "\#17 cultivated land protection" and "\#13 mechanism" revolve around issues such as soil use and pollution governance and cultivated land protection and food security. Food security constitutes the basis of national development, and the protection of cultivated land and soil is a priority among priorities for national food security. Thus, research in this regard is of strategic significance.

- Water resources management

Water resources provide an essential foundation for human existence. Driven by economic development and population growth, the eco-environmental water demand of society is increasing every year. The contradiction between supply and demand of water resources is also gradually highlighted and further intensified by water pollution. According to the obtained clustering results, clusters "\#12 semi-arid areas in northwestern China", "\#9 calculation of water resources bearing capacity", and "\#8 runoff" can be summarized as problems related to water resources management. Water resources-related keywords have less semantics, and research directions in this field are more condensed. Problems of great concern in this category include the hydrological effect of forest cover, the calculation of the water resources bearing capacity, water security, and water pollution.

- Sustainable development

The concept of "sustainable development" first appeared in the World Conservation Strategy in 1980 as a resources management strategy. Later, it was embraced and employed by scholars in philosophy, economics, sociology, and many other fields [25]. After the UN Conference on the Environment and Development in 1992, China began to actively implement a sustainable development strategy. Since 1996, China has made many outstanding sustainable development achievements and produced many high-quality studies, especially in the field of resources and environmental sciences. In this study, clustering analysis was performed on the keyword "sustainable development" (time slicing $=5$ years) to analyze its research development path. According to the results of the analysis: (1) The first highly cited paper on sustainable development was published in 1996 and mainly introduced the concept and connotations of sustainable development. (2) In 1997-2001, sustainable development was associated with the following keywords: 1. "Evaluation indices" and "ecological footprint". The main research content was the establishment of an evaluation index system for sustainable development, such as the application effects of the ecological footprint as an evaluation index for sustainable development in different spatial areas [26]. 2. "Ecotourism" and "ecological planning": A typical example was the path towards the sustainable utilization of ecotourism as a tourism landscape resource [27]. (3) In 2002-2006, the research contents of sustainable development became more extensive and began to co-occur with the following keywords: 1 . "Energy value analysis" and "policy suggestions"; 2. "eco-environmental water demand"; 3. "food security"; 4. "ecosystem services"; and 5. "ecological security" and "ecological bearing capacity". Clearly, in this period, close attention was paid to the sustainable development paths and policies of various kinds of resources. Sustainable development is not only a development path but also a development goal. (4) In 2007-2011, no keyword co-occurred with sustainable development, indicating that sustainable development research in this period was not very prominent but inherited the research hotspots and basis of existing studies. As a result, highly cited papers on sustainable development were absent. (5) Since 2012, guided by national policies, sustainable development was interconnected with eco-civilization construction. 


\subsubsection{Developmental Stages of Resources and Environmental Science Research in China}

As shown by the above literature review, China's highly cited papers on resources and environmental sciences can be analyzed according to three stages, each with distinct research directions and research hotspots. The advance of research further leads to more extensive research directions and stronger interdisciplinarity.

Stage 1: Introductory stage (1987-1997): No keyword cluster emerged in this stage, mainly for the following two reasons: First, the selected journals had merely been founded at this stage, and highly cited papers were rare. Second, there was also a lack of prominent research hotspots and influential research subjects. This stage mainly concentrated on concepts, definitions, and literature research. In the previous five years, the economy mode was plan-led, and the central government dominated the macro-economic administration including the allocation of natural resources. The resources and environmental issues had not come on stage as a subject. Correspondingly, most studies were on the conceptual and framework research in the field.

Stage 2: Developmental stage (1997-2006): This stage was a high-producing period of highly cited papers on resources and environmental sciences. Land resources, water resources, ecology, and sustainable development were classical research problems in the field of resources and environmental sciences. At this stage, both the amount and influence of the literature increased. The priorities at this stage focused on the establishment and measurement of an evaluation index system for resources and the environment and the sustainable utilization paths and policies of resources and the environment. In this stage, the industrialization of the rural area was the national mainstream policy, which made the protection of rural land, water, and the ecological environment urgent social problems. Therefore, the evaluation, measurement, and protection of the resources and environments were the critically key issues in this stage.

Stage 3: Deepening stage (2007-today): The existing highly cited papers mainly concentrate on energy and eco-civilization construction. Energy and carbon emissions are the research frontiers of resources and environmental sciences, while the construction of ecocivilization constitutes the policy guidance. Land, water, ecology, and research problems remain research hotspots in this field. Because of the formation of mature research theories and paradigms, existing studies are mainly supplementary or case studies, and their influence is not as prominent as that of the previous classical literature. It can be predicted that sustainable development research will have a considerably long extension period in the field of resources and environmental sciences and that many mature studies on sustainable development will appear in the field of resources and environmental sciences. Currently, sustainable development is a widely recognized, scientific, and effective development path. Faced by limited resources, sustainable development research remains an important research direction for resources and environmental sciences.

\section{Conclusions, Limitations, and Prospects}

\subsection{Conclusions}

To identify China's latest research trends in the field of resources and environmental science for international academic circles, this study selected the top $1 \%$ of papers in terms of total citation frequency in the field of resources and environmental sciences from five CSSCI journals sourced from CNKI (the most authoritative national core literature retrieval system). CiteSpace was then employed to identify the research institutions, research groups, core author groups, and research hotspots of resources and environmental sciences and the evolution of research hotspots in China. The aim was to explore the recent development trends of resources and environmental research in China. The following findings can be summarized:

Resources and environmental research in China is advancing towards more extensive research directions and stronger interdisciplinarity. The research hotspots of resources and environmental science in China mainly focus on five directions, namely carbon emissions, eco-civilization construction, land use and intensive management, water resources manage- 
ment, and pollution governance. The sustainable development of various resources and environmental elements remains a major research trend.

China's highly cited papers on resources and environmental sciences are completed in most cases through cooperation between authors and in a few cases independently by individual authors. Teamwork will remain the prevailing development trend in the future. Empirical results have shown that there is poor connectedness between cooperation networks, that intergroup cooperation is rare, and that scientists are largely connected by their research institutions. The integration of new scholars may lead to the emergence of new research fields and directions for research groups. The key to future development lies in introducing new research forces and strengthening intergroup cooperation.

China's academic papers on resources and environmental sciences are still predominantly published by scientific research institutions and institutions of higher learning, while extraordinary high-level corporate research institutions are rarely involved. In the future, large-scale resources and environmental enterprises should be encouraged to take part in high-end research projects. The Institute of Geographic Sciences and Natural Resources Research, CAS, is the most influential research institution in the field of resources and environmental sciences in China. Beijing and Nanjing are the high-producing areas of highly cited papers. Currently, there is a lack of close cooperation relationships, regular information communication, and clustered academic groups between research institutions and enterprises applying resources and environmental science. In this case, academic networks composed of multiple research entities will be able to promote knowledge transfer, information communication, and disciplinary development and should be encouraged to produce more high-quality studies. The findings of this study have implications for the establishment of scientific research funds and for policy making in China.

\subsection{Limitations and Prospects}

\subsubsection{Limitations}

All CSSCI journals in the field of resources and environmental sciences have been used as samples. However, there is a great variety of journals focusing on resources and environmental sciences in China; thus, certain studies on resources and the environment may be missing from this study, making the analysis incomplete. In the future, further journals can be selected from this field for further analysis or comparison. In addition, when CiteSpace is used, no co-citation analysis can be performed on the Chinese data from CNKI to explore the evolution of knowledge bases and research subjects in this field, and thus, the research on hotspot problems should be further refined and deepened based on keyword co-occurrence. With the perfection of software, co-citation analysis can be conducted in the future on papers about resources and environmental sciences to deepen research on the academic development process and trend.

\subsubsection{Prospects}

This study helps to clarify the academic development process and trend of resources and environmental sciences. It also provides a decision-making basis for academic research and practice in this field. Currently, energy, carbon emissions, and eco-civilization construction are all major research frontiers in this field. In the future, researchers can carry their research forward, focusing on specific problems such as energy consumption, atmospheric environment governance, low-carbon development, ecosystem service functions, eco-civilization construction, intensive land use, and water pollution governance. Regarding the establishment of scientific research funds and policy making, the state should actively encourage cross-institution and cross-disciplinary cooperation to promote the transfer of knowledge and information. Academic groups should continuously absorb new research and new vitality and cultivate young talents under the guidance of core scholars. 


\begin{abstract}
Author Contributions: Conceptualization, G.H. and R.L.; methodology, M.Z.; software, M.Z.; formal analysis, M.Z.; investigation, H.L.; resources, K.S.; writing-original draft preparation, G.H.; writingreview and editing, G.H.; supervision, R.L.; funding acquisition, R.L. All authors have read and agreed to the published version of the manuscript.
\end{abstract}

Funding: The project funded by the Key Project of National Social Science Foundation of China 20AZD115, the National Natural Science Foundation of China 71573158.

Institutional Review Board Statement: Not applicable.

Informed Consent Statement: Not applicable.

Data Availability Statement: Not applicable.

Acknowledgments: We would like to express our gratitude to Chen Zongsheng who offered the guidance to the project.

Conflicts of Interest: The authors declare no conflict of interest.

\title{
References
}

1. Ding, Z.; Fan, W.; Feng, R.; Chang, X. Sixty years of the resource and environmental science research in CAS. Bull. Chin. Acad. Sci. 2009, 24, 351-361.

2. Si, H.; Shi, J.; Tang, D.; Wen, S.; Miao, W.; Duan, K. Application of the theory of planned behavior in environmental science: A comprehensive bibliometric analysis. Int. J. Environ. Res. Public Health 2019, 16, 2788. [CrossRef]

3. Zhang, M.; Gao, Z.; Zheng, T.; Ma, Y.; Wang, Q.; Gao, M.; Sun, X. A bibliometric analysis of biodiesel research during 1991-2015. J. Mater. Cycles Waste 2018, 20, 10-18. [CrossRef]

4. Zhang, C.; Fang, Y.; Chen, X.; Congshan, T. Bibliometric analysis of trends in global sustainable livelihood research. Sustainability 2019, 11, 1150. [CrossRef]

5. Qin, H.; Prasetyo, Y.; Bass, M.; Sanders, C.; Prentice, E.; Nguyen, Q. Seeing the forest for the trees: A bibliometric analysis of environmental and resource sociology. Soc. Nat. Resour. 2020, 33, 1131-1148. [CrossRef]

6. Zhengwei, W.; Hongmei, Y. Highly Cited Papers on Urban Public Security Research: A Bibliometric Analysis. In E3S Web of Conferences, Proceedings of the International Conference on Building Energy Conservation Thermal Safety and Environmental Pollution Control, Hefei, China, 1-3 November 2019; EDP Sciences: Les Ulis, France, 2019; p. 4095.

7. Ji, L.; Liu, C.; Huang, L.; Huang, G. The evolution of Resources Conservation and Recycling over the past 30 years: A bibliometric overview. Resour. Conserv. Recycl. 2018, 134, 34-43. [CrossRef]

8. Zhen-Liang, X.U.; Guo, X.C. The evolution course of the research fronts of international technological innovation in fifty years -Based on view of scientific knowledge mapping. Stud. Sci. Sci. 2012, 1, 44-59.

9. Gao, X. Review of several scientific issues of resources and environmental research. Adv. Earth Sci. 2000, 15, 321-327.

10. Suo-Jun, D.U. Advances in Environmental Risk Assessment. Environ. Sci. Manag. 2006, 31, 193-194.

11. Tong, Z.Q.; Lei, G.U.; Jian-Hua, M.A. Some Ponderations on the Basic Principles of Environmental Science. J. Henan Univ. Nat. Sci. 2012, 42, 167-173.

12. Bengang, L.I.; Shuying, L. Environmental science for the 21st century-Meeting the challenge from complex environmental systems. Acta Sci. Circumst. 2011, 6, 1121-1132.

13. Lin, F.; Yang, J. The evolution of the research hotspots and discipline structure in environmental science of China: A quantitative analysis base on bibliometrics. Stud. Sci. Sci. 2016, 34, 1294-1300.

14. Hong, H.; Yang, L.; Division, M.S. Trends of Research Hotspots and Funded in Division of Resource and Environmental Policy and Management from NSFC in 1990-2015. Chin. J. Environ. Manag. 2016, 8, 13-17.

15. Yaru, D.; Xuejiao, L.I.; Suzhen, S.; Samp, C.A. Cooperation Network Analysis of Environmental Scientific Research. J. Intell. 2013, $32,71-79$.

16. Sun, H. Fourty years of the resource and environmental science research in CAS. Bull. Chin. Acad. Sci. 1989, 4, 321-326.

17. Wang, X.; Zhang, Z.; Xiao, X. Tendency Analysis of Resources and Environment Sciences of Chinese Academy of Sciences Based on Bibliometrics. Adv. Earth Sci. 2015, 30, 1287-1293.

18. Chen, C. Searching for intellectual turning points: Progressive knowledge domain visualization. Proc. Natl. Acad. Sci. USA 2004, 101, 5303-5310. [CrossRef]

19. Chen, Y.; Chen, C.; Hu, Z.; Wang, X. Principles and Applications of Analyzing a Citation Space; Science Press: Beijing, China, 2014; pp. 10-15.

20. Otte, E.; Rousseau, R. Social network analysis: A powerful strategy, also for the information sciences. J. Inf. Sci. 2002, 28, 441-453. [CrossRef]

21. Eisenberg, D.; Freed, G.L.; Eisenberg, D.; Freed, G.L. Statistics and Analysis of the High-cited Papers of Information Science Research from 2004 to 2008. J. Intell. 2010, 23, 975-978.

22. Qiu, J.; Wu, C. Study on the Co-Author Relationship of Informetrics Based on Social Network Analysis. Doc. Inf. Knowl. 2011, 6, 12-17. 
23. Ying, J. A co-word analysis of bibliometrics in 1995-2004. J. China Soc. Sci. Tech. Inf. 2006, 25, 503-512.

24. Weixian, W.; Ma, X. Optimal Policy for Energy Structure Adjustment and Haze Governance in China. China Popul. Resour. Environ. 2015, 25, 6-14.

25. Guo, H. Big Earth data facilitates sustainable development goals. Acta Chir. Belg. 2021, 36, 874-884. [CrossRef]

26. Pomè, A.P.; Tagliaro, C.; Ciaramella, G. A Proposal for Measuring In-Use Buildings' Impact through the Ecological Footprint Approach. Sustainability 2021, 13, 355. [CrossRef]

27. Omarzadeh, D.; Pourmoradian, S.; Feizizadeh, B.; Khallaghi, H.; Sharifi, A.; Kamran, K.V. A GIS-based multiple ecotourism sustainability assessment of West Azerbaijan province, Iran. J. Environ. Plan. Manag. 2021, 10, 1-24. [CrossRef] 